\title{
Resistance to Antimalarial Drugs: Molecular, Pharmacologic, and Clinical Considerations
}

\author{
MARK A. TRAVASSOS AND MIRIAM K. LAUFER \\ Center for Vaccine Development, University of Maryland School of Medicine, Baltimore, Maryland 21201
}

\begin{abstract}
One of the greatest obstacles to the control of malaria has been the spread of resistance to drugs used on a large scale. This review provides an update of the current understanding of the molecular basis for antimalarial drug resistance. Parasite intrinsic resistance is just one component that determines the in vivo efficacy of a drug. Human immune responses and pharmacologic properties play important roles in determining the clinical outcome of treatment. The emergence and spread of resistance also results from an interplay of these factors. Current efforts to characterize and deter resistance to new combination therapy are also discussed. (Pediatr Res 65: 64R-70R, 2009)
\end{abstract}

$\mathrm{O}$ ne of the greatest obstacles to the control of malaria has been the spread of resistance to drugs used on a large scale. Malaria continues to cause hundreds of millions of infections per year, and the annual toll of one million deaths is exacted predominantly on African children (1). Until several years ago, the armamentarium to battle malaria was essentially limited to two drugs for the treatment of uncomplicated malaria and one drug to treat severe disease. Resistance to chloroquine and sulfadoxine-pyrimethamine (SP) has fueled the on-going burden of Plasmodium falciparum malaria. In response, the World Health Organization (WHO) has recommended the use of combination treatments that include artemisinin derivatives as first-line therapy. Seventy-seven of the 81 countries worldwide with endemic $P$. falciparum have now adopted the WHO recommendation (1). New drugs, even when used in combination, are not impervious to resistance. In this review, we will discuss our current understanding of the mechanisms of resistance to antimalarial drugs, factors that affect the clinical response to therapy aside from intrinsic resistance and also features that contribute to the spread of resistance.

\section{Overview of Important Drugs for the Treatment of Malaria in Endemic Countries}

Until recently, chloroquine was the most widely used drug to treat and prevent malaria infection. The spread of chloroquine resistance in Africa led to a rise in the disease burden in the 1980s $(2,3)$, a setback that has plagued the region to this day. Chloroquine acts by interfering with the detoxification of

Received February 5, 2008; accepted February 9, 2009.

Correspondence: Miriam Laufer, M.D., M.P.H., Center for Vaccine Development, University of Maryland School of Medicine, 685 W. Baltimore Street, HSF-1 Room 480, Baltimore, MD 21201; e-mail: mlaufer@medicine.umaryland.edu

Supported by NIAID/NIH (M.A.T.), NIAID/NIH, Doris Duke Charitable Foundation and Pfizer (M.K.L.). hematin, a toxic byproduct of Hb degradation, in the Plasmodium parasite's food vacuole. Although it is no longer recommended for the treatment of P. falciparum, it is the drug of choice to treat $P$. vivax and $P$. ovale, less severe forms of malaria that can cause recurrent infections.

With the spread of chloroquine resistance, many countries adopted SP as the first-line antimalarial treatment. SP is composed of two drugs that act on sequential enzymes in the folate synthesis pathway. When both drugs are used together, they act synergistically. Although SP is a coformulation of two drugs, it is not considered combination therapy because the mechanisms of action are closely linked. Resistance to SP spread more quickly than to chloroquine. In Southeast Asia, its use was abandoned after only 5 years (4). SP resistance is more common in East Africa than West Africa (5). SP use is likely to continue even as first-line therapy for uncomplicated malaria changes. SP is increasingly used for the intermittent preventive treatment of malaria in vulnerable groups including pregnant women, a widely adopted practice, and infants and children, tools that have not been implemented on a large scale.

In response to resistance to the widely available antimalarials used as monotherapy, artemisinin-based combination therapy (ACTs) have been introduced first in Asia and now throughout Africa and South America. The artemisinins are derived from the Chinese sweet wormwood plant, Artemisia апnиa. Their mechanism of action has not been fully elucidated, but they may inhibit the sarco/endoplasmic reticulum calcium ATPase found in Plasmodium parasites (6). Artemisinins are potent antimalarials, acting rapidly and killing Plasmodium parasites throughout the asexual blood stages $(7,8)$. Artemisinins may also decrease malaria transmission because they act on the gametocytes, the parasite stage that is infectious to the mosquito vector (9). Artesunate cannot be administered alone because if the duration of therapy is less than 5-7 $\mathrm{d}$, there is a high risk of recrudescent infection. The recurrent parasites are not resistant to artemisinins but evade their very short duration of action (10). When combined with a longeracting partner drug, the artemisinins can be administered as an ACT over 3 days. The commonly used ACTs are artemether-

\footnotetext{
Abbreviations: ACT, artemisinin-based combination therapy; DHFR, dihydrofolate reductase; DHPS, dihydropteroate synthetase; PfCRT, Plasmodium falciparum chloroquine-resistance transporter; PfMDR, Plasmodium falciparum multidrug resistance gene; SP, sulfadoxine-pyrimethamine; WHO, World Health Organization
} 
lumefantrine, amodiaquine-artesunate, and mefloquineartesunate.

\section{The Molecular Basis of Drug Resistance}

P. falciparum chloroquine-resistance transporter. Among chloroquine-resistant parasites, there is a decrease in the accumulation of drug within the food vacuole. Genetic crosses have identified the role of the $P$. falciparum chloroquineresistance transporter (PfCRT) $(11,12)$. When present in a mutated form, it is associated with decreased chloroquine accumulation. Multiple polymorphisms in the gene are associated with chloroquine resistance both in vitro and in vivo, but the essential mutation seems to be the replacement of lysine with threonine at residue 76 (13-15). However, PfCRT is not the sole molecular determinant of chloroquine resistance. Mutations in the homolog of the major multidrugtransporter $P$. falciparum multidrug resistance gene (PfMDR) seems to modulate the extent of chloroquine resistance conferred by mutations in PfCRT. In vitro studies suggest that the genetic background of the strain also influences the degree of resistance conferred by these mutations in PfCRT and PfMDR (16,17).

Dihydrofolate reductase and dihydropteroate synthetase. De novo folate synthesis is essential to parasite survival. The antifolate medications interrupt this process by targeting two enzymes: pyrimethamine and proguanil target dihydrofolate reductase (DHFR), and sulfa drugs such as sulfadoxine target dihydropteroate synthase (DHPS). Resistance to antifolate drugs is the result of the accumulation of mutations in DHFR and DHPS. Nonsynonymous nucleotide changes occur in a stepwise fashion leading to increasing parasite resistance to antifolate drugs (18). The order in which mutations occur is likely due to changes in enzymatic activity with each additional mutation, although the data are not clear (19). The highest levels of antifolate resistance are found in Southeast Asia and South America. In these two regions, a polymorphism at DHFR residue 164 is almost always found. In contrast, DHFR I164L has not spread through sub-Saharan Africa, despite extensive use of the drug (4). Although SP is ineffective in treating symptomatic disease in malaria-naïve children in many parts of Africa, it has retained some efficacy in preventing malaria in pregnant women (20). This may be due to the moderate level of resistance conferred by the polymorphisms in DHFR and DHPS typically found in Africa and the absence of the I164L polymorphism associated with very high-level SP resistance (up to 20,000-fold decrease in susceptibility in comparison with the wild type). It is unclear as to why this final mutation has not taken hold in Africa, despite extensive drug pressure. It has been hypothesized that this amino acid change carries a high fitness cost to the parasite, such that it is unable to survive the immune response of malaria-experienced hosts in Africa (21).

The worldwide spread of drug resistance. Tracing the spread of the chloroquine-resistant genotype of PfCRT has led to the current understanding that chloroquine resistance developed in several independent locations in Asia, Papua New Guinea, and South America (22). The chloroquine-resistant gene that originated in Southeast Asia spread across the Asian continent and reached Africa in the late 1970s $(17,23)$. Over the course of a decade, chloroquine resistance became widespread in sub-Saharan Africa. Resistance did not emerge within infected individuals on a regular basis, as might be expected based on the inherent mutation rate of the parasite and the high rate of replication within the human host. Rather, resistant strains emerged a limited number of times and those ancestral strains spread in the permissive environment of drug pressure.

Faced with widespread chloroquine resistance, many countries in sub-Saharan Africa adopted SP as first-line therapy in the 1990s. Resistant parasites appeared shortly thereafter. Low-level antifolate resistance arises within a population independently. This was suspected based on early studies of pyrimethamine prophylaxis (24) and has since been supported by microsatellite analysis demonstrating diverse origins of DHFR genes carrying one or two mutations. However, moderate antifolate resistance, the highest level of resistance found in Africa is associated with three mutations in DHFR and has limited ancestral origins. In parasites carrying these "triple mutations" the gene seems to have originated in southeast Asia and migrated to Africa, much like chloroquine resistance, with no or limited evidence of recent local evolution $(25,26)$.

There has been one example of the effect of the removal of drug pressure on the prevalence of drug-resistant parasites. In 1993, Malawi was the first country to replace chloroquine with SP for the oral treatment of malaria, due to high rates of chloroquine resistance. Immediately after chloroquine use was stopped, there was a decrease in the prevalence of the PfCRT 76T polymorphism that is associated with chloroquine resistance (27). From 2001 until today, no chloroquine-resistant parasites have been identified in the major cities where surveillance has occurred [(28) and F. Dzinjalamala, unpublished data]. A clinical trial demonstrated that chloroquine is now highly effective in the treatment of malaria, after high rates of failure documented just 12 y prior (29). Chloroquine should not be used in sub-Saharan Africa at this time because chloroquine-resistant parasites predominate in most countries. As chloroquine is withdrawn from use throughout the region, it is possible that chloroquine-susceptible parasites will return and chloroquine may once again play a role in the treatment or prevention of malaria in the future.

P. falciparum multidrug resistance gene. The gene encoding PfMDR is an ortholog of P-glycoproteins found in mammals that mediate multidrug resistance in cancer cells. The protein is found on the digestive vacuole membrane and seems to play a role in regulating traffic across the membrane, including a variety of antimalarial drugs $(16,30)$. The substitution N86Y in PfMDR modulates but is not essential to chloroquine resistance. In clinical studies, this polymorphism is not associated with changes in treatment outcome $(13,31)$. Mutations in this gene have also been linked to in vitro susceptibility of other drugs, but the effects depend on the genetic background of the malaria strain and are not uniform. The allele associated with chloroquine resistance (86Y) has also been associated with hypersensitivity to mefloquine, 
when assessed in vitro. The clinical implications of the decrease in $50 \%$ inhibitory concentration $\left(\mathrm{IC}_{50}\right)$ are not known (32). Of recent interest, PfMDR N86, the chloroquine susceptible-allele has been proposed as a molecular marker for lumefantrine resistance. Artemether-lumefantrine treatment selects for N86 in recurrent infections (33).

Differences in $p f m d r$ copy number are linked to changes in clinical efficacy of several drugs. Increases in copy number are associated with increased risk of treatment failure after treatment with mefloquine, artesunate-mefloquine, or artemetherlumefantrine (34-36). Relating copy number to in vitro susceptibility testing has been difficult because copy number can change during the process of culture adaptation of field isolates, a process that is necessary for reliable assessment of drug sensitivity. Sidhu et al. (37) have succeeded in altering $p f m d r$ copy number and have demonstrated increases in susceptibility to mefloquine, quinine, halofantrine, and artemisinin with lower copy number.

There may be other genes in the Plasmodium genome with increased copy numbers in response to drug pressure. GTP-cyclohydrolase I ( $g c h l)$, the first gene in the folate biosynthesis pathway, is increased in copy number in regions with extensive antifolate drug usage. The increased gchl copy number (ranging from 1 to 11 ) is exclusively found in parasites with polymorphisms in DHFR and DHPS associated with antifolate resistance. It has been suggested that this increase in copy number plays a role in compensating for the changes in enzyme activity associated with antifolate resistance, rather than mediating the decrease in susceptibility (38).

PfATP6. Another transporter, PfATP6, is an ortholog of the mammalian sarcoendoplasmic reticulum $\mathrm{Ca}^{2+}$ ATPase (SERCA). There is evidence that this pump is inhibited by artemisinins, suggesting that mutations may alter artemisinin susceptibility (6). One molecular marker for artemisinin resistance has been proposed, PfATP6 S769N, based on an ecological study in Senegal, French Guiana, and Cambodia and supported by differences in $\mathrm{IC}_{50}$ values (39). The most susceptible parasites were found in Cambodia, where the nucleotide substitution was not identified, and the most resistant parasites were found in French Guiana in association with the polymorphism at residue 769 . The role of this polymorphism in conferring or serving as a marker for artemisinin resistance has not been confirmed. This single nucleotide polymorphism (SNP) is not found in China, where the artemisinins have been used the longest (40) nor has it been identified in Africa $(41,42)$.

\section{Pharmacologic Contributions to Drug Resistance and Impaired Efficacy}

When used as monotherapy, artemisinins are associated with recurrent parasitemia unless the medication is administered for 5-7 d. The need for prolonged therapy has been considered a significant obstacle to adherence. As a result, the artemisinins are administered with longer acting partner drugs in a fixed-dose combination treatment regimen that is used to protect against recrudescent infections. The artemisinin deriv- ative rapidly reduces parasitemia, with the remaining parasites are eliminated by the longer-acting partner drug. For example, artemether-lumefantrine was the first fixed-dose combination commercially produced for use in Africa. Artemether acts rapidly, with a half-life of $1-3 \mathrm{~h}$, whereas lumefantrine, with a half-life of 3-6 d, is responsible for preventing the recurrent parasitemia associated with short course artemisinin therapy.

For long-acting drugs, blood levels persist for days, a period during which a patient essentially has antimalarial monotherapy. This time interval has been referred to as the "selective window," a period of time when the drug level is adequate to suppress the growth of susceptible parasites but too low to prevent the replication of drug-resistant parasites $(43,44)$. Watkins and Mosobo (45) were the first to characterize the selective window of pyrimethamine. They sampled children who were treated with SP and collected parasites from cases of recurrent parasitemia. They found that parasites that occurred before $52 \mathrm{~d}$ after initial therapy were almost all pyrimethamine-resistant, whereas after $52 \mathrm{~d}$, the $\mathrm{IC}_{50}$ values were similar to the baseline distribution. This study was performed before the validation of molecular markers for resistance. Using PfMDR 86 as the marker of lumefantrine resistance, the selective window of lumefantrine has been estimated to last approximately $12 \mathrm{~d}$, based on a model derived from one clinical trial (46). This value is a rough estimate, since the basis of lumefantrine resistance has not been completely elucidated and is not fully represented by the single polymorphism.

ACTs combine the short-acting artemisinins with longeracting partner drugs, and were initially introduced in Southeast Asia, where transmission intensity is low and exposure to a new infection after therapy is rare. In contrast, in sub-Saharan Africa, where transmission is intense, individuals who have recently been treated for malaria infection are frequently exposed to new infections during the period of time when the partner drug level is waning. If new infections occur during the selection window of the partner drug, drug-resistant parasites will have a survival advantage. There is concern that frequent exposures of parasites to subtherapeutic drug levels may allow for the rapid emergence of drug resistance. Data from studies in Africa indicate that the use of ACTs leads to the selection of parasites resistant to the long-acting partner drugs (47-49). The long-term effect of this selection is not yet known.

The role of pharmacokinetics in determining antimalarial efficacy and in promoting the emergence and spread of drug resistance has recently gained increased attention (50). In the past, drug levels were rarely measured, so that all episodes of clinical treatment failure were thought to be due to inherent parasite resistance. In fact, if therapeutic drug levels are not achieved, clinical outcomes are an inaccurate reflection of drug efficacy and parasite susceptibility. This has become especially clear with the use of lumefantrine, a compound that has highly variable absorption, determined by fat consumption, among other factors. Low lumefantrine level $7 \mathrm{~d}$ after therapy is an independent risk factor for recurrent parasitemia (35). Because pharmacokinetic analysis of drugs is beyond the scope of standard drug efficacy trials, some investigators have 
proposed including the assessment of the drug level at $\mathrm{d} 7$ as a key data point to determine whether therapeutic concentrations were achieved in the blood (51). This will offer important information about the contribution of pharmacokinetic factors to the observed clinical efficacy of a drug.

Incomplete understanding of pharmacokinetic factors may shorten the useful life of antimalarial drugs and may hasten the spread of resistance. When dose-finding studies are conducted, they take place before resistance to the study drug has emerged. The dose selected is usually the lowest dose that achieves a good response so as to minimize adverse effects. As resistance spreads, low levels of drug allow the spread of resistant parasites because the therapeutic levels required to clear mildly resistant parasites is higher than the level required to eliminate fully susceptible ones (52). A PK mathematical model has suggested that had mefloquine been deployed at a dose of $24 \mathrm{mg} / \mathrm{kg}$ rather than $15 \mathrm{mg} / \mathrm{kg}$, mefloquine resistance would have emerged much more slowly (53). One such natural experiment has occurred in Guinea Bissau, where chloroquine has been used at two to three times the dose administered in other countries $(50-75 \mathrm{mg} / \mathrm{kg}$ vs. $25 \mathrm{mg} / \mathrm{kg}$ administered over $3 \mathrm{~d}$ ) (54). Chloroquine resistance is rare there in contrast to most of its neighbors (55). These observations should be taken with caution: the causal relationship between high dose and low prevalence of resistance has not been established, and the safety of the dosing regimen has not been rigorously evaluated.

Counterfeit medication. During the past decade, the malaria community has become aware that antimalarial drug quality is a cause for concern. Counterfeit and low quality antimalarial medications are found worldwide. The most thoroughly investigated drugs are the artemisinins. Recently, an international, multidisciplinary team was established to identify and trace fake artemisinins and hold their producers accountable. The group obtained specimens from most countries in Southeast Asia and discovered that half of the samples were counterfeit. Counterfeit drugs contained much less than the labeled amount of active drug or none at all. In tablets labeled as artesunate and other artemisinin derivatives, the contents included antimicrobials, nonartemisinin antimalarials, antipyretics, and even illicit drugs and carcinogenic compounds (56). Although fake artemisinins brought attention to the issue of antimalarial quality, the integrity of all antimalarials has undergone investigation on a small scale. Testing of a variety of different antimalarials across sub-Saharan Africa found substandard medication in seven countries $(57,58)$. Aside from the obvious threat of counterfeit antimalarials administered to sick patients who require full doses of the medication, drugs that contain less than the labeled amount of drug may contribute to the spread of drug resistance.

\section{The Human Host}

The host immune response to malaria infection likely influences the speed of spread of drug resistance and also the extent to which drug resistance translates into clinical drug failure (59). Immunity to malaria is acquired through repeated exposure to infection and is maintained through boosting by infectious bites throughout an individual's lifetime. In high transmission settings, children are susceptible to symptomatic and severe malaria infection, whereas adults are considered semi-immune because they can acquire infection, but are not at risk for severe disease and often experience asymptomatic infection. Malaria parasites in these semi-immune adults are not under drug pressure because infection is not usually recognized or treated. In contrast, individuals in low and sporadic transmission settings, such as Southeast Asia, are not exposed to malaria with enough frequency to develop immunity. As a result, all infected individuals develop symptomatic infection, and the infections always prompt treatment with an antimalarial drug. It is possible that the difference in the extent of drug pressure on the parasite population drives the spread of drug resistance. As described above, resistant parasites have emerged in low transmission settings, where most parasites in human hosts are under selective drug pressure, and later spread to high transmission settings, where many parasites survive without drug pressure.

Another factor that has limited the spread of drug resistance in high transmission settings is the ability of the host immune response to clear resistant infections. Individuals with acquired immunity are cured even if the parasites are resistant to the administered drug. Because no laboratory correlate for immunity has been established for malaria, age is used as a surrogate measure of acquired immunity in endemic areas. Several studies have demonstrated that with increasing age, there is improved ability to clear resistant parasites. Some of this impaired clearance in children may be due to subtherapeutic dosing (52), but lack of acquired immunity is likely also a major factor. Intrinsic parasite drug resistance may be less apparent in endemic areas as drugs retain clinical efficacy even against resistant parasites due to host factors (60-62). Figure 1 demonstrates the lack of consistency between the results of clinical drug efficacy studies and intrinsic parasite resistance when host and pharmacokinetic factors are taken into account.

Red blood cell abnormalities. There are a number of human genetic polymorphisms that offer protection against malaria, including enzyme deficiencies such as glucose-6-phosphate dehydrogenase deficiency and pyruvate kinase deficiency and $\mathrm{Hb}$ variants such as thalassemia and $\mathrm{Hb} \mathrm{S} \mathrm{(63).} \mathrm{Little} \mathrm{is} \mathrm{known} \mathrm{about}$ how effectively patients with these polymorphisms respond to antimalarial drugs. There is evidence that antimalarials in patients with hemoglobinopathies have different pharmacokinetic properties $(64,65)$, and that standard doses of antimalarials may be less efficacious (66). In human populations with high prevalence of these hemoglobinopathies, drug efficacy may seem impaired, even in the absence of intrinsic resistance or may be threatened by even minimal increases in $\mathrm{IC}_{50} \mathrm{~s}$.

HIV. The interaction between HIV and malaria has been difficult to measure. Although malaria does not act like an opportunistic infection for people living with HIV infection who have previously acquired malaria immunity, it is significantly more severe in malaria-naive hosts with HIV coinfection than without HIV infection (67). In most settings, HIV infection is associated with higher parasite densities than in the absence of 


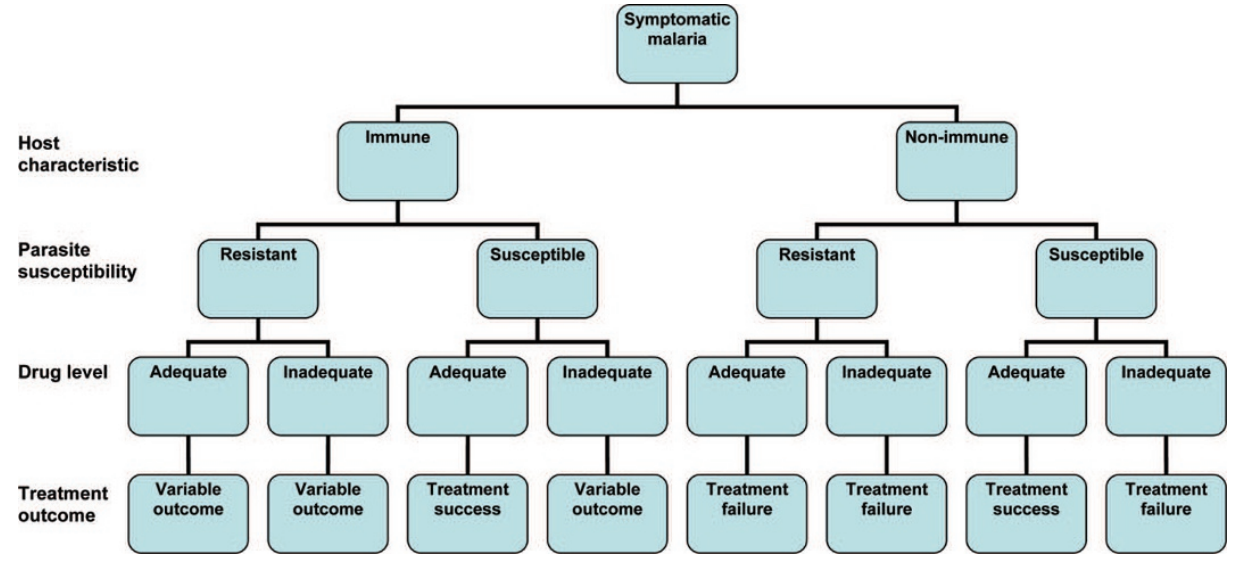

Figure 1. Schematic depiction of the clinical outcomes of drug efficacy studies when taking into account parasite, pharmacokinetic, and host factors.
HIV infection. This trend has led to the suggestion that HIV infection leads to an increase in the parasite biomass by $18 \%$ (68). Increased biomass raises the possibility that mutations associated with drug resistance may emerge more frequently than in the absence of coinfection.

\section{Identifying and Deterring Resistance to New Drugs}

Like resistance to chloroquine and SP, resistance to the artemisinins may be emerging in Southeast Asia. Thailand and Cambodia adopted the ACT mefloquine-artesunate in 1995 and 2000, respectively. Several studies reported decreases in the efficacy of the combination $(69,70)$, but it has been difficult to ascertain whether the decline was due to the artesunate or mefloquine. In 2006, Noedl et al. conducted a randomized trial comparing artesunate monotherapy for $7 \mathrm{~d}$ to treatment with quinine and tetracycline (a regimen that is expected to be very effective) in western Cambodia. Four of the 60 participants treated with artesunate had recurrent parasitemia 3 to 4 wks after therapy. Two of these individuals were found to have subtherapeutic drug levels, so the clinical failure was not attributed to parasite drug resistance. The parasites from the other two individuals were found to have artemisinin $\mathrm{IC}_{50} \mathrm{~S}$ that were four times higher than those of the parasites collected from study subjects with a good response to therapy. The proposed molecular markers for artemisinin resistance, $p f m d r$ copy number and SERCA polymorphisms, were not associated with artemisinin resistance in this pilot study (71).

An international initiative is underway to further investigate the possibility of artemisinin resistance in the region of the Thai-Cambodian border. Led by the WHO and funded by the Bill and Melinda Gates Foundation, the Artemisinin Resistance Confirmation, Characterization and Containment project (ARC3), is conducting trials of artesunate monotherapy to assess its efficacy without the complication of a partner drug. Parasites collected from these studies will undergo in vitro susceptibility testing and extensive genomic analysis to understand the molecular basis of artemisinin resistance. If resistance is confirmed, genomic tools will be applied to identify markers of artemisinin resistance and to begin to understand its molecular basis. Investigators, policy makers, and donors will work together to contain artemisininresistant malaria so that ACTs can remain as effective therapy in the regions hardest-hit by malaria.
The proactive effort to identify and contain the very earliest sign of artemisinin resistance is an example of a new, aggressive international effort to not just control, but to eradicate malaria from the world (http://rbm.who.int/gmap/gmap.pdf, last accessed January 17, 2009). A cornerstone of the current malaria eradication plan is deterring the emergence and spread of drug resistance. The Worldwide Antimalarial Resistance Network (WWARN) has been established to monitor antimalarial drug efficacy so as to maximize the useful therapeutic lives of current drugs and to detect emergence as rapidly as possible [(72) and website www.wwarn.org]. Drugs alone will not be able to eradicate this disease: other key elements to the strategy include vector control and vaccine development. Nevertheless, malaria will not be controlled without effective medication for treatment and prevention. The loss of antimalarial drug efficacy has led to the tragic persistence of malaria transmission in many regions of the world and is a cycle that cannot be repeated.

Acknowledgment. We are grateful to Chris Plowe for his helpful comments.

\section{REFERENCES}

1. World Health Organization 2008 World Malaria Report 2008. WHO, Geneva

2. Trape JF, Legros F, Ndiaye P, Konate L, Bah IB, Diallo S, Verdier F, Hatin I, Le Bras J 1989 Chloroquine-resistant Plasmodium falciparum malaria in Senegal. Trans R Soc Trop Med Hyg 83:761

3. Zucker JR, Ruebush TK, Obonyo C, Otieno J, Campbell CC 2003 The mortality consequences of the continued use of chloroquine in Africa: experience in Siaya, western Kenya. Am J Trop Med Hyg 68:386-390

4. Sibley CH, Hyde JE, Sims PF, Plowe CV, Kublin JG, Mberu EK, Cowman AF, Winstanley PA, Watkins WM, Nzila AM 2001 Pyrimethamine-sulfadoxine resistance in Plasmodium falciparum: what next? Trends Parasitol 17:582-588

5. Wongsrichanalai C, Pickard AL, Wernsdorfer WH, Meshnick SR 2002 Epidemiology of drug-resistant malaria. Lancet Infect Dis 2:209-218

6. Eckstein-Ludwig U, Webb RJ, Van Goethem ID, East JM, Lee AG, Kimura M, O'Neill PM, Bray PG, Ward SA, Krishna S 2003 Artemisinins target the SERCA of Plasmodium falciparum. Nature 424:957-961

7. ter Kuile F, White NJ, Holloway P, Pasvol G, Krishna S 1993 Plasmodium falciparum: in vitro studies of the pharmacodynamic properties of drugs used for the treatment of severe malaria. Exp Parasitol 76:85-95

8. White NJ 2008 Qinghaosu (artemisinin): the price of success. Science 320:330-334

9. Pukrittayakamee S, Chotivanich K, Chantra A, Clemens R, Looareesuwan S, White NJ 2004 Activities of artesunate and primaquine against asexual- and sexual-stage parasites in falciparum malaria. Antimicrob Agents Chemother 48:1329-1334

10. Ittarat W, Pickard AL, Rattanasinganchan P, Wilairatana P, Looareesuwan S, Emery K, Low J, Udomsangpetch R, Meshnick SR 2003 Recrudescence in artesunatetreated patients with falciparum malaria is dependent on parasite burden not on parasite factors. Am J Trop Med Hyg 68:147-152 
11. Wellems TE, Walker-Jonah A, Panton LJ 1991 Genetic mapping of the chloroquineresistance locus on Plasmodium falciparum chromosome 7. Proc Natl Acad Sci USA 88:3382-3386

12. Fidock DA, Nomura T, Talley AK, Cooper RA, Dzekunov SM, Ferdig MT, Ursos LM, Sidhu AB, Naude B, Deitsch KW, Su XZ, Wootton JC, Roepe PD, Wellems TE 2000 Mutations in the $P$. falciparum digestive vacuole transmembrane protein PfCRT and evidence for their role in chloroquine resistance. Mol Cell 6:861-871

13. Diimde A, Doumbo OK, Cortese JF, Kayentao K, Doumbo S, Diourte Y, Dicko A, Su XZ, Nomura T, Fidock DA, Wellems TE, Plowe CV, Coulibaly D 2001 A molecular marker for chloroquine-resistant falciparum malaria. $\mathrm{N}$ Engl J Med 344:257-263

14. Durand R, Jafari S, Vauzelle J, Delabre JF, Jesic Z, Le Bras J 2001 Analysis of pfcrt point mutations and chloroquine susceptibility in isolates of Plasmodium falciparum. Mol Biochem Parasitol 114:95-102

15. Lakshmanan V, Bray PG, Verdier-Pinard D, Johnson DJ, Horrocks P, Muhle RA, Alakpa GE, Hughes RH, Ward SA, Krogstad DJ, Sidhu AB, Fidock DA 2005 A critical role for PfCRT K76T in Plasmodium falciparum verapamil-reversible chloroquine resistance. EMBO J 24:2294-2305

16. Valderramos SG, Fidock DA 2006 Transporters involved in resistance to antimalarial drugs. Trends Pharmacol Sci 27:594-601

17. Cooper RA, Hartwig CL, Ferdig MT 2005 pfcrt is more than the Plasmodium falciparum chloroquine resistance gene: a functional and evolutionary perspective. Acta Trop 94:170-180

18. Plowe CV, Cortese JF, Djimde A, Nwanyanwu OC, Watkins WM, Winstanley PA, Estrada-Franco JG, Mollinedo RE, Avila JC, Cespedes JL, Carter D, Doumbo OK 1997 Mutations in Plasmodium falciparum dihydrofolate reductase and dihydropteroate synthase and epidemiologic patterns of pyrimethamine-sulfadoxine use and resistance. J Infect Dis 176:1590-1596

19. Gregson A, Plowe CV 2005 Mechanisms of resistance of malaria parasites to antifolates. Pharmacol Rev 57:117-145

20. Ter Kuile FO, van Eijk AM, Filler SJ 2007 Effect of sulfadoxine-pyrimethamine resistance on the efficacy of intermittent preventive therapy for malaria control during pregnancy: a systematic review. JAMA 297:2603-2616

21. Nzila A, Ochong E, Nduati E, Gilbert K, Winstanley P, Ward S, Marsh K 2005 Why has the dihydrofolate reductase 164 mutation not consistently been found in Africa yet? Trans R Soc Trop Med Hyg 99:341-346

22. Wootton JC, Feng X, Ferdig MT, Cooper RA, Mu J, Baruch DI, Magill AJ, Su XZ 2002 Genetic diversity and chloroquine selective sweeps in Plasmodium falciparum. Nature 418:320-323

23. Wellems TE, Plowe CV 2001 Chloroquine-resistant malaria. J Infect Dis $184: 770-776$

24. Clyde DF 1954 Observations on monthly pyrimethamine (daraprim) prophylaxis in an East African village. East Afr Med J 31:41-46

25. Maiga O, Djimde AA, Hubert V, Renard E, Aubouy A, Kironde F, Nsimba B, Koram K, Doumbo OK, Le Bras J, Clain J 2007 A shared Asian origin of the triple-mutant dhfr allele in Plasmodium falciparum from sites across Africa. J Infect Dis 196:165-172

26. Roper C, Pearce R, Nair S, Sharp B, Nosten F, Anderson T 2004 Intercontinental spread of pyrimethamine-resistant malaria. Science 305:1124

27. Kublin JG, Cortese JF, Njunju EM, Mukadam RA, Wirima JJ, Kazembe PN, Djimde AA, Kouriba B, Taylor TE, Plowe CV 2003 Reemergence of chloroquine-sensitive Plasmodium falciparum malaria after cessation of chloroquine use in Malawi. J Infect Dis 187:1870-1875

28. Nkhoma S, Molyneux M, Ward S 2007 Molecular surveillance for drug-resistant Plasmodium falciparum malaria in Malawi. Acta Trop 102:138-142

29. Laufer MK, Thesing PC, Eddington ND, Masonga R, Dzinjalamala FK, Takala SL, Taylor TE, Plowe CV 2006 Return of chloroquine antimalarial efficacy in Malawi. N Engl J Med 355:1959-1966

30. Rohrbach P, Sanchez CP, Hayton K, Friedrich O, Patel J, Sidhu AB, Ferdig MT, Fidock DA, Lanzer M 2006 Genetic linkage of pfmdr1 with food vacuolar solute import in Plasmodium falciparum. EMBO J 25:3000-3011

31. Duah NO, Wilson MD, Ghansah A, Abuaku B, Edoh D, Quashie NB, Koram KA 2007 Mutations in Plasmodium falciparum chloroquine resistance transporter and multidrug resistance genes, and treatment outcomes in Ghanaian children with uncomplicated malaria. J Trop Pediatr 53:27-31

32. Woodrow CJ, Krishna S 2006 Antimalarial drugs: recent advances in molecular determinants of resistance and their clinical significance. Cell Mol Life Sci 63:1586-1596

33. Sisowath C, Stromberg J, Martensson A, Msellem M, Obondo C, Bjorkman A, Gil JP 2005 In vivo selection of Plasmodium falciparum pfmdr1 86N coding alleles by artemether-lumefantrine (Coartem). J Infect Dis 191:1014-1017

34. Alker AP, Lim P, Sem R, Shah NK, Yi P, Bouth DM, Tsuyuoka R, Maguire JD, Fandeur T, Ariey F, Wongsrichanalai C, Meshnick SR 2007 Pfmdr1 and in vivo resistance to artesunate-mefloquine in falciparum malaria on the Cambodian-Thai border. Am J Trop Med Hyg 76:641-647

35. Price RN, Uhlemann AC, van Vugt M, Brockman A, Hutagalung R, Nair S, Nash D, Singhasivanon P, Anderson TJ, Krishna S, White NJ, Nosten F 2006 Molecular and pharmacological determinants of the therapeutic response to artemetherlumefantrine in multidrug-resistant Plasmodium falciparum malaria. Clin Infect Dis 42:1570-1577

36. Price RN, Uhlemann AC, Brockman A, McGready R, Ashley E, Phaipun L, Patel R, Laing K, Looareesuwan S, White NJ, Nosten F, Krishna S 2004 Mefloquine resistance in Plasmodium falciparum and increased pfmdr1 gene copy number. Lancet 364:438-447

37. Sidhu AB, Uhlemann AC, Valderramos SG, Valderramos JC, Krishna S, Fidock DA 2006 Decreasing pfmdr1 copy number in Plasmodium falciparum malaria heightens susceptibility to mefloquine, lumefantrine, halofantrine, quinine, and artemisinin. J Infect Dis 194:528-535

38. Nair S, Miller B, Barends M, Jaidee A, Patel J, Mayxay M, Newton P, Nosten F, Ferdig MT, Anderson TJ 2008 Adaptive copy number evolution in malaria parasites. PLoS Genet 4:e1000243

39. Jambou R, Legrand E, Niang M, Khim N, Lim P, Volney B, Ekala MT, Bouchier C, Esterre P, Fandeur T, Mercereau-Puijalon O 2005 Resistance of Plasmodium falciparum field isolates to in-vitro artemether and point mutations of the SERCAtype PfATPase6. Lancet 366:1960-1963

40. Zhang G, Guan Y, Zheng B, Wu S, Tang L 2008 No PfATPase6 S769N mutation found in Plasmodium falciparum isolates from China. Malar J 7:122

41. Mugittu K, Genton B, Mshinda H, Beck HP 2006 Molecular monitoring of Plasmodium falciparum resistance to artemisinin in Tanzania. Malar J 5:126

42. Ferreira ID, Lopes D, Martinelli A, Ferreira C, Do Rosario VE, Cravo P 2007 In vitro assessment of artesunate, artemether and amodiaquine susceptibility and molecular analysis of putative resistance-associated mutations of Plasmodium falciparum from Sao Tome and Principe. Trop Med Int Health 12:353-362

43. Stepniewska K, White NJ 2008 Pharmacokinetic determinants of the window of selection for antimalarial drug resistance. Antimicrob Agents Chemother 52:1589-1596

44. Nyunt MM, Plowe CV 2007 Pharmacologic advances in the global control and treatment of malaria: combination therapy and resistance. Clin Pharmacol Ther 82:601-605

45. Watkins WM, Mosobo M 1993 Treatment of Plasmodium falciparum malaria with pyrimethamine-sulfadoxine: selective pressure for resistance is a function of long elimination half-life. Trans R Soc Trop Med Hyg 87:75-78

46. Hastings IM, Ward SA 2005 Coartem (artemether-lumefantrine) in Africa: the beginning of the end? J Infect Dis 192:1303-1304

47. Djimde AA, Fofana B, Sagara I, Sidibe B, Toure S, Dembele D, Dama S, Ouologuem D, Dicko A, Doumbo OK 2008 Efficacy, safety, and selection of molecular markers of drug resistance by two ACTs in Mali. Am J Trop Med Hyg 78:455-461

48. Holmgren G, Gil JP, Ferreira PM, Veiga MI, Obonyo CO, Bjorkman A 2006 Amodiaquine resistant Plasmodium falciparum malaria in vivo is associated with selection of pfcrt 76T and pfmdr1 86Y. Infect Genet Evol 6:309-314

49. Martensson A, Stromberg J, Sisowath C, Msellem MI, Gil JP, Montgomery SM, Olliaro P, Ali AS, Bjorkman A 2005 Efficacy of artesunate plus amodiaquine versus that of artemether-lumefantrine for the treatment of uncomplicated childhood Plasmodium falciparum malaria in Zanzibar, Tanzania. Clin Infect Dis 41:1079-1086

50. Barnes KI, Lindegardh N, Ogundahunsi O, Olliaro P, Plowe CV, Randrianarivelojosia M, Gbotosho GO, Watkins WM, Sibley CH, White NJ 2007 World Antimalarial Resistance Network (WARN) IV: clinical pharmacology. Malar J 6:122

51. White NJ, Stepniewska K, Barnes K, Price RN, Simpson J 2008 Simplified antimalarial therapeutic monitoring: using the day-7 drug level? Trends Parasitol 24:159-163

52. Barnes KI, Watkins WM, White NJ 2008 Antimalarial dosing regimens and drug resistance. Trends Parasitol 24:127-134

53. Simpson JA, Watkins ER, Price RN, Aarons L, Kyle DE, White NJ 2000 Mefloquine pharmacokinetic-pharmacodynamic models: implications for dosing and resistance. Antimicrob Agents Chemother 44:3414-3424

54. Kofoed PE, Lopez F, Johansson P, Sandstrom A, Hedegaard K, Aaby P, Rombo L 2002 Treatment of children with Plasmodium falciparum malaria with chloroquine in Guinea-Bissau. Am J Trop Med Hyg 67:28-31

55. Ursing J, Schmidt BA, Lebbad M, Kofoed PE, Dias F, Gil JP, Rombo L 2007 Chloroquine resistant $P$. falciparum prevalence is low and unchanged between 1990 and 2005 in Guinea-Bissau: an effect of high chloroquine dosage? Infect Genet Evol 7:555-561

56. Newton PN, Fernandez FM, Plancon A, Mildenhall DC, Green MD, Ziyong L, Christophel EM, Phanouvong S, Howells S, McIntosh E, Laurin P, Blum N, Hampton CY, Faure K, Nyadong L, Soong CW, Santoso B, Zhiguang W, Newton J, Palmer K 2008 A collaborative epidemiological investigation into the criminal fake artesunate trade in South East Asia. PLoS Med 5:e32

57. Atemnkeng MA, De Cock K, Plaizier-Vercammen J 2007 Quality control of active ingredients in artemisinin-derivative antimalarials within Kenya and DR Congo. Trop Med Int Health 12:68-74

58. Bate R, Coticelli P, Tren R, Attaran 2008 A Antimalarial drug quality in the most severely malarious parts of Africa-a six country study. PLoS ONE 3:e2132

59. Hastings IM 2006 Complex dynamics and stability of resistance to antimalarial drugs. Parasitology 132:615-624

60. Djimde AA, Doumbo OK, Traore O, Guindo AB, Kayentao K, Diourte Y, Niare-Doumbo S, Coulibaly D, Kone AK, Cissoko Y, Tekete M, Fofana B, Dicko A, Diallo DA, Wellems TE, Kwiatkowski D, Plowe CV 2003 Clearance of drug-resistant parasites as a model for protective immunity in Plasmodium falciparum malaria 1. Am J Trop Med Hyg 69:558-563

61. Laufer MK, van Oosterhout JJ, Thesing PC, Dzinjalamala FK, Hsi T, Beraho L, Graham SM, Taylor TE, Plowe CV 2007 Malaria treatment efficacy among people living with HIV: the role of host and parasite factors. Am J Trop Med Hyg 77:627-632

62. Hoffman SL, Masbar S, Hussein PR, Soewarta A, Harun S, Marwoto HA, Campbell JR, Smrkovski L, Purnomo, Wiady I 1984 Absence of malaria mortality in villagers with chloroquine-resistant Plasmodium falciparum treated with chloroquine. Trans R Soc Trop Med Hyg 78:175-178

63. Min-Oo G, Gros P 2005 Erythrocyte variants and the nature of their malaria protective effect 6. Cell Microbiol 7:753-763 
64. Ittarat W, Looareesuwan S, Pootrakul P, Sumpunsirikul P, Vattanavibool P, Meshnick SR 1998 Effects of alpha-thalassemia on pharmacokinetics of the antimalarial agent artesunate. Antimicrob Agents Chemother 42:2332-2335

65. Kamchonwongpaisan S, Chandra-ngam G, Avery MA, Yuthavong Y 1994 Resistance to artemisinin of malaria parasites (Plasmodium falciparum) infecting alphathalassemic erythrocytes in vitro. Competition in drug accumulation with uninfected erythrocytes 1. J Clin Invest 93:467-473

66. Mockenhaupt FP, May J, Bergqvist Y, Meyer CG, Falusi AG, Bienzle U 2001 Evidence for a reduced effect of chloroquine against Plasmodium falciparum in alpha-thalassaemic children. Trop Med Int Health 6:102-107

67. Laufer MK, Plowe CV 2007 The Interaction between HIV and malaria in Africa Curr Infect Dis Rep 9:47-54

68. Van Geertruyden JP, Menten J, Colebunders R, Korenromp E, D’Alessandro U 2008 The impact of HIV-1 on the malaria parasite biomass in adults in sub-Saharan Africa contributes to the emergence of antimalarial drug resistance. Malar J 7:134
69. Denis MB, Tsuyuoka R, Poravuth Y, Narann TS, Seila S, Lim C, Incardona S, Lim P, Sem R, Socheat D, Christophel EM, Ringwald P 2006 Surveillance of the efficacy of artesunate and mefloquine combination for the treatment of uncomplicated falciparum malaria in Cambodia. Trop Med Int Health 11:1360-1366

70. Vijaykadga S, Rojanawatsirivej C, Cholpol S, Phoungmanee D, Nakavej A, Wongsrichanalai C 2006 In vivo sensitivity monitoring of mefloquine monotherapy and artesunate-mefloquine combinations for the treatment of uncomplicated falciparum malaria in Thailand in 2003. Trop Med Int Health 11:211-219

71. Noedl H, Se Y, Schaecher K, Smith BL, Socheat D, Fukuda MM 2008 Evidence of artemisinin-resistant malaria in western Cambodia. N Engl J Med 359:26192620

72. Sibley CH, Barnes KI, Watkins WM, Plowe CV 2008 A network to monitor antimalarial drug resistance: a plan for moving forward. Trends Parasitol 24:43-48 